\title{
ESTERIFICAÇÃO ENZIMÁTICA DE ÁCIDOS GRAXOS DE ÓLEO DE COCO UTILIZANDO LIPASE DE Candida antarctica
}

\author{
E. A. CARNEIRO' ${ }^{1}$, M. L. MARQUES ${ }^{2}$, L. R. B. GONÇALVES ${ }^{2}$ \\ ${ }^{1}$ Instituto Federal do Ceará \\ ${ }^{2}$ Universidade Federal do Ceará, Departamento de Engenharia Química \\ E-mail para contato: elizabetecarneiro@ifce.edu.br
}

\begin{abstract}
RESUMO - Avaliou-se a influência dos parâmetros reacionais na esterificação dos ácidos graxos do óleo de coco com álcool etilíco, visando à obtenção de biodiesel via rota enzimática utilizando lipase de Candida antarctica (CALB) imobilizada covalentemente. Foi utilizado um suporte à base de quitosana previamente ativado com glicidol, etilenodiamina e glutaradeído, sendo este comparado com o derivado comercial de CALB. Os seguintes parâmetros de síntese foram investigados: razão molar, temperatura e efeito da adição de zeólita. Foi avaliado o perfil de conversão ao longo do tempo de reação e a estabilidade operacional do derivado. Observou-se que quando a razão molar foi menor, maior a conversão obtida, 73,25 \%. A temperatura em que o biocatalisador obteve maior conversão foi de $45{ }^{\circ} \mathrm{C}$ e na avaliação da estabilidade operacional o derivado manteve sua atividade por 10 ciclos de síntese.
\end{abstract}

\section{INTRODUÇÃO}

Na busca da remediação de uma série de problemas associados à produção de biodiesel, como formação de sabões no processo, elevado consumo de energia (devido à alta temperatura de reação) e produção de grande quantidade de efluentes, a utilização de enzimas como catalisadores é uma alternativa que vem sendo amplamente estudada. A síntese enzimática do biodiesel traz uma série de vantagens, o glicerol pode ser facilmente recuperado sem tratamento complexo, a temperatura de reação é mais baixa e, além disso, as enzimas podem ser facilmente recuperadas e reutilizadas (Kulkarni et al., 2006).

As enzimas na forma solúvel são, normalmente, menos estáveis que os catalisadores químicos e não podem ser usadas em condições severas, pela possível desnaturação e consequente perda de atividade (Svendsen et al., 1997). Desta forma, a imobilização em suportes inertes assegura o aumento da concentração de biocatalisador por volume de reator, o reuso das enzimas e minimiza o custo de separação dos produtos, desta forma superando o inconveniente econômico associado ao seu uso. A quitosana que é extraída de rejeitos da indústria pesqueira, principalmente das carapaças dos crustáceos, vem sendo bastante utilizada como suporte de baixo custo para a imobilização de enzimas (Krajewska, 2004).

Este trabalho teve como objetivo avaliar o potencial de aplicação de um biocatalisador de baixo custo para a aplicação na reação de esterificação de matérias-primas com elevado teor de 
ácidos graxos livres, visando à obtenção de biodiesel a partir dos ácidos graxos do óleo de coco por rota etílica. Foram avaliados diversos parâmetros na esterificação dos ácidos graxos: razão molar dos substratos, quantidade de enzima imobilizada, temperatura e efeito da retirada de água por adsorção. Após avaliação das melhores condições de síntese, foi realizada a cinética da reação e a avaliação da estabilidade operacional dos derivados obtidos através de ciclos sucessivos de esterificação.

\section{MATERIAL E MÉTODOS}

\subsection{Material}

Lipase de Candida antarctica (CALB) na forma solúvel e imobilizada, Novozym 435 (Novozymes Latin America Ltd.-Brasil). Como suporte para imobilização foi utilizado quitosana (Polymar Ind Ltda.-Brasil) associada ao alginato de sódio, preparado na proporção quitosana 2,5\% alginato 2,5\%, ativado com epicloridrina, segundo Adriano et al. (2008). Na reação de esterificação foram utilizados álcool etílico absoluto 99,5\% (v/v) da Synth (São Paulo) e o óleo de coco (Cocos nucifera L.) bruto foi fornecido pela FORT COCO Indústria e Comércio de Coco Ltda, Itaitinga (Ceará, Brasil). O óleo de coco utilizado foi previamente hidrolisado via ultrassom para a obtenção dos ácidos graxos, segundo metodologia proposta por Lima (2010), após a etapa de hidrólise. O índice de acidez do óleo e dos ácidos graxos obtidos foram 6,00 \pm 0,21 mg KOH/g e 198,28 \pm 1,35 $\mathrm{mg} \mathrm{KOH/g}$, respectivamente. Todos os outros reagentes utilizados foram de grau analítico.

\subsection{Métodos}

Imobilização da enzima: A lipase foi colocada em contato com o suporte quitosana 2,5\% alginato 2,5\%, ativado com epicloridrina (quitosana - CALB) através da solução de enzima (65 U por grama de suporte) em tampão bicarbonato $100 \mathrm{mM}, \mathrm{pH} 10$ na razão de $1 / 10(\mathrm{~m} / \mathrm{v})$, rotação de 20 $\mathrm{rpm}$, a $25{ }^{\circ} \mathrm{C}$ durante $5 \mathrm{~h}$. Uma unidade de atividade enzimática (U) foi definida como a quantidade de enzima capaz de hidrolisar $1 \mu \mathrm{mol}$ de butirato de para-nitrofenila (PNPB) por minuto (Kordel et al. 1991).

Índice de acidez e cálculo da conversão: A determinação da acidez do óleo de coco e de seus ácidos graxos foi efetuada usando o método AOCS 5a-40 que consiste na utilização de solução de $\mathrm{NaOH}$ para titulação do ácido graxo livre na amostra, segundo metodologia adotada por Moreto e Fett (1998). O índice de acidez foi quantificado de acordo com a Equação 1.

$$
I A(m g K O H / g)=\frac{V \times f \times 56,11 \times M}{m}
$$

em que: IA é o índice de acidez (mg KOH/g), V é o volume de solução de $\mathrm{NaOH}$ necessário para 
titular a amostra $(\mathrm{mL})$, f é o fator de correção da solução de $\mathrm{NaOH}, \mathrm{M}$ é a molaridade da solução de $\mathrm{NaOH}(\mathrm{M}=\mathrm{mol} / \mathrm{L})$, m é a massa da amostra utilizada, 56,11 é o fator de correção com relação ao $\mathrm{KOH}$.

A conversão foi calculada pelo acompanhamento da redução do índice de acidez de acordo com a Equação 2. Este cálculo foi possível, pois à medida que os ésteres vão sendo formados, a quantidade de ácidos graxos livres (AGL) diminui e, portanto, o índice de acidez decresce.

$$
X(\%)=\left(\frac{I A_{0}-I A_{f}}{I A_{0}}\right) \times 100
$$

em que: $\mathrm{X}$ é a taxa de redução do índice de acidez na reação (\%), $\mathrm{IA}_{\mathrm{o}}$ é o índice de acidez do ácido/óleo no início da reação e $\mathrm{IA}_{\mathrm{f}}$ é o índice de acidez no final da reação.

Síntese dos ésteres etílicos: As reações foram realizadas em erlenmeyers de $50 \mathrm{~mL}$ fechados, a quantidade de biocatalisador foi de 1,0\% $\left(\mathrm{m}_{\text {derivado }} / \mathrm{m}_{\text {óleo }}\right)$, com quantidade de enzima oferecida de 65 $\mathrm{U} / \mathrm{g}$. Os frascos foram mantidos sob agitação rotacional de $150 \mathrm{rpm}$ e, inicialmente, à temperatura de $40^{\circ} \mathrm{C}$. As melhores condições obtidas para a síntese dos ésteres etilícos foram utilizadas para o estudo de estabilidade operacional dos biocatalisadores preparados.

A estabilidade operacional da enzima imobilizada foi avaliada, para os melhores parâmetro de síntese, através de ciclos sucessivos com duração de 24 horas da reação. Ao final de cada ciclo, o derivado foi removido do meio reacional e lavado com o solvente hexano para ser utilizado na síntese seguinte.

\section{RESULTADOS E DISCUSSÃO}

\subsection{Síntese de ésteres etílicos a partir dos ácidos graxos de óleo de coco}

Efeito da razão molar: A Figura 1 mostra os resultados para a avaliação da influência da razão molar óleo:álcool, na conversão dos ésteres etílicos em função da quantidade de etanol presente no meio reacional. $\mathrm{O}$ aumento da razão molar acarreta uma diminuição na conversão obtida, sendo a conversão máxima obtida para razão molar 1:1, 73,25 \% para o derivado obtido em laboratório, e $81,86 \%$ para Novozym 435. Trubiano et al. (2007), na síntese de ésteres de ácidos graxos utilizando a lipase de Candida antarctica, verificaram o mesmo efeito para a razão molar. Provavelmente, o excesso de álcool provocou a inativação da enzima, pois esta pode sofre inibição pelo álcool. 


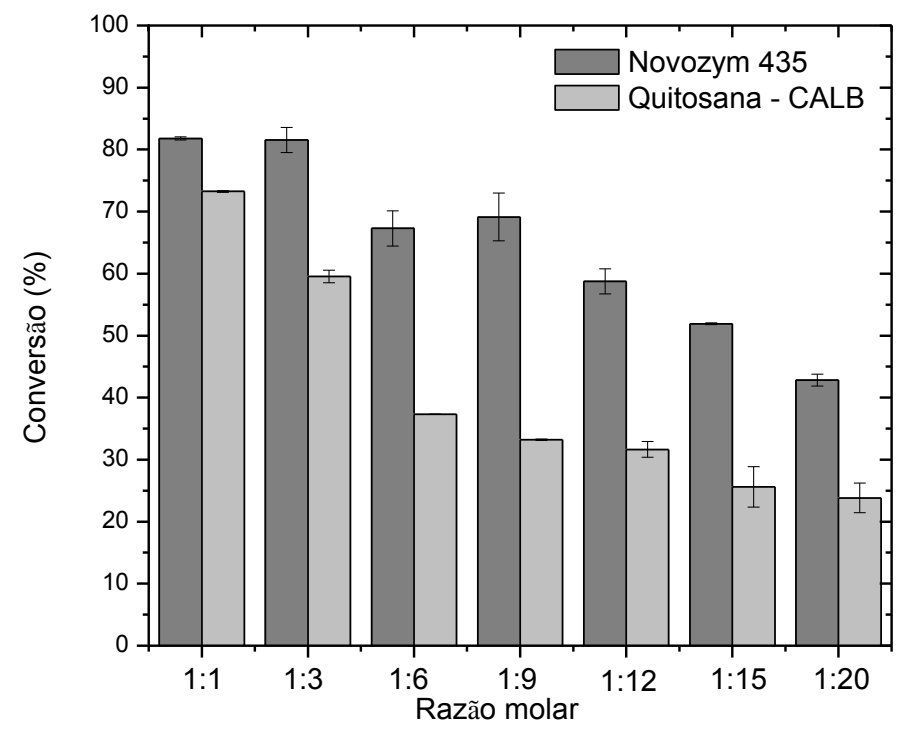

Figura 1 - Efeito da razão molar na conversão, quantidade de derivado 1,0 \% (m/m), $150 \mathrm{rpm}$, temperatura de $40{ }^{\circ} \mathrm{C}, 8$ horas de reação, Novozym 435 ( $\square$ ) e Quitosana - CALB ( $\square$ ).

Remoção da água: A adição de $20 \%$ de zeólita $\left(\mathrm{m}_{\text {zeólita }} / \mathrm{m}_{\text {óleo }}\right)$ no meio reacional para a reação de 8 horas e para um tempo de reação de 24 horas não resultou em aumento da conversão, como mostra a Figura 2.

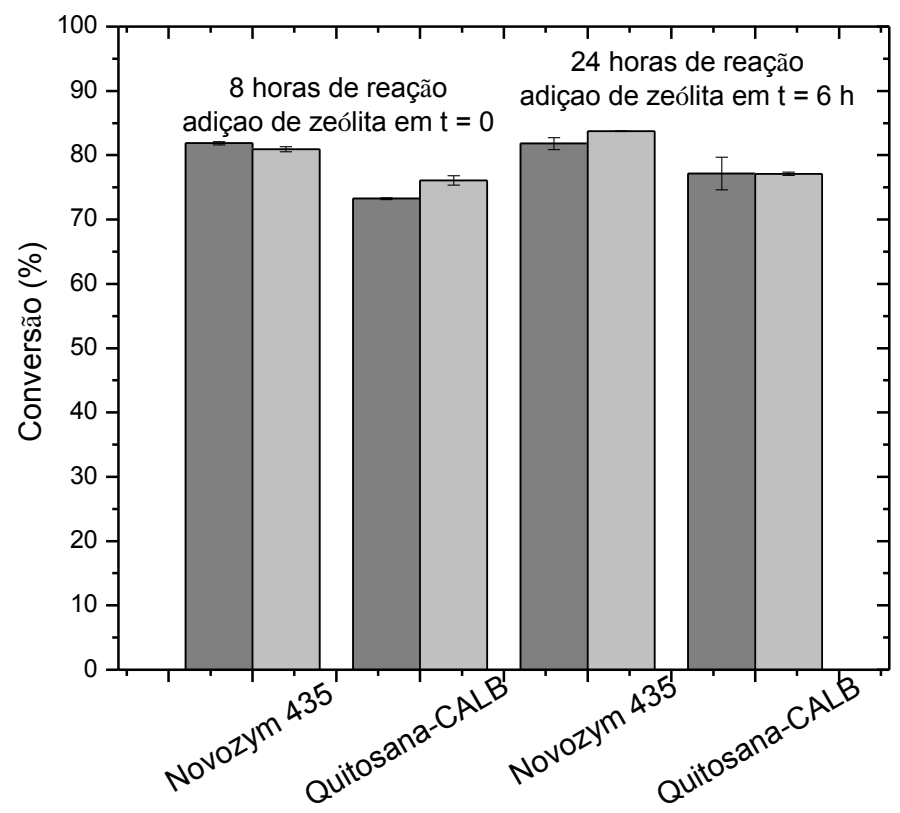

Figura 2 - Efeito da adição de zeólita na conversão, razão molar 1:1, quantidade de derivado 1,0 \% $(\mathrm{m} / \mathrm{m}), 150 \mathrm{rpm}$, temperatura de $40{ }^{\circ} \mathrm{C}$, sem zeólita (匹) e com zeólita ( $\left.\square\right)$. 
Efeito da temperatura: Na Figura 3 são observados os resultados obtidos para o estudo do efeito da temperatura na conversão enzimática dos ésteres etílicos.

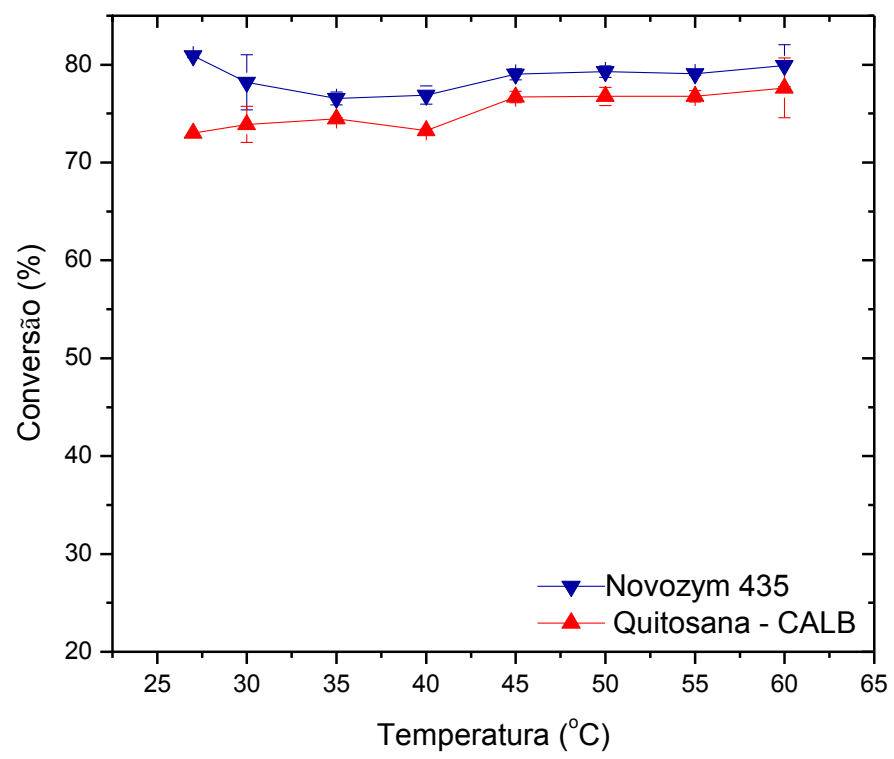

Figura 3 - Efeito da temperatura na conversão, razão molar 1:1, quantidade de derivado 1,0 \% (m/m), 150 rpm, 8 horas de reação, Novozym 435 (匹) e Quitosana - CALB (匹).

Os resultados obtidos mostram que o derivado de CALB em quitosana apresentou um acréscimo na conversão em torno de $3 \%$ a partir da temperatura de $45^{\circ} \mathrm{C}$ com conversão em torno de $77 \%$, valores e perfis de conversão similares foram obtidos para o biocatalisador comercial Novozym 435, sendo para este os valores um pouco maiores (cerca de $2 \%$ ), cerca de $79 \%$ de conversão. Os resultados obtidos mostram que a CALB mantém sua atividade catalítica em amplas faixas de temperaturas, na literatura há relatos de que se trata de uma enzima termoestável (Kirk e Christensen, 2002), e o derivado obtido em laboratório apresentou atividade e estabilidade compatíveis com o derivado comercial, nas condições avaliadas, demonstrando que o processo de imobilização conferiu uma maior proteção à molécula de proteína.

Perfil de conversão e estabilidade operacional: A Figura 4 mostra o perfil de conversão enzimática dos ésteres etílicos e a Figura 5 mostra o perfil da estabilidade operacional com relação à conversão, baseada em ciclos de síntese. 


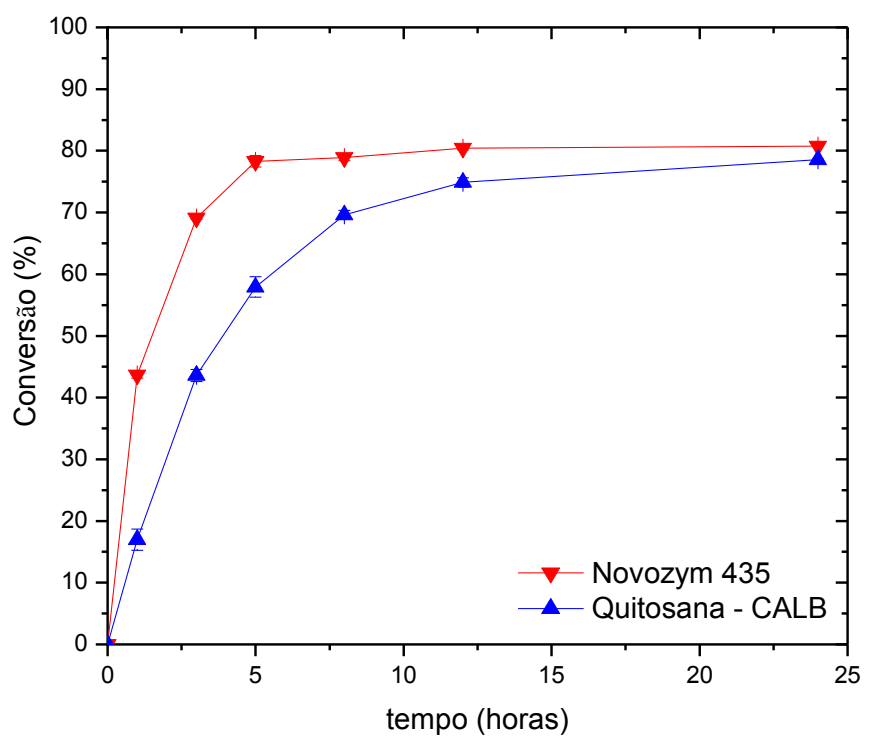

Figura 4 - Avaliação do perfil de conversão em função do tempo, razão molar 1:1, quantidade de derivado 1,0\% (m/m), $150 \mathrm{rpm}$, a $45{ }^{\circ} \mathrm{C}$, Novozym 435 (匹) e Quitosana - CALB (匹).

A avaliação da conversão em função do tempo mostra que a conversão máxima para o derivado comercial, Novozym 435, é ligeiramente maior que a observada para o derivado de quitosana e os valores de conversão iniciais para o derivado obtido em laboratório foram menores, provavelmente devido à ocorrência de limitação difusional. 


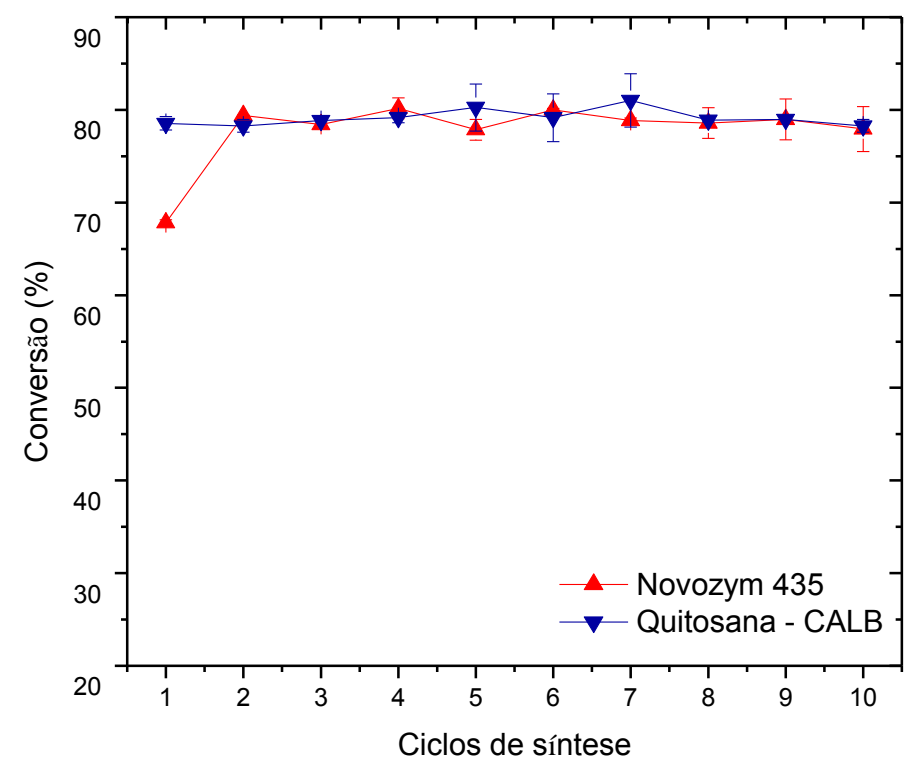

Figura 5 - Perfil da estabilidade operacional com relação à conversão, baseada em ciclos de síntese, razão molar 1:1, quantidade de derivado $1,0 \%(\mathrm{~m} / \mathrm{m}), 150 \mathrm{rpm}, 24$ horas de reação, a $45{ }^{\circ} \mathrm{C}$, Novozym 435 ( $\mathbf{a})$ e Quitosana - CALB ( $\mathbf{\square})$.

$\mathrm{Na}$ avaliação da estabilidade operacional o derivado de CALB obtido em laboratório e o comercial mantiveram sua atividade por 10 bateladas de síntese de ésteres de ácidos graxos.

\section{CONCLUSÕES}

Quanto menor a razão molar maior foi a conversão obtida, 73,25 \% para o derivado de CALB obtido em laboratório. A adição de zeólita para os tempos de reação de 8 horas e 24 horas não resultou em aumento da conversão. A temperatura em que os biocatalisadores obtiveram maior conversão foram para temperaturas maiores que $45{ }^{\circ} \mathrm{C}$. O derivado de CALB manteve sua atividade até o final de 10 ciclos.

Os resultados comprovam a viabilidade da catálise enzimática para produção de biodiesel a partir de substratos de elevada acidez livre, já que o alto custo da enzima é um fator que restringe a produção industrial de ésteres por essa rota alternativa. $\mathrm{O}$ derivado produzido através da imobilização covalente multipontual em quitosana obteve desempenho compatível com o derivado comercial disponível no mercado a um alto custo. 


\section{REFERÊNCIAS}

ADRIANO, W. S; MENDONÇA, D.; RODRIGUES, D. S.; MAMMARELLA, E.; GIORDANO, R. L. C. Improving the properties of chitosan as support for the covalent multipoint immobilization of chymotrypsin. Biomacromolecules, v. 9, p. 2170-2179, 2008.

KIRK, O.; CHRISTENSEN, M.W. Lipases from Candida antarctica: Unique Biocatalysts from a Unique Origin, Org. Process Res. Dev., v. 6, p. 446-451, 2002.

KORDEL, M.; HOFMANN, B.; SCHOMBURG, D.; SCHIMID, R. D. Extracellular lipase of Pseudomonas sp strain ATCC-21808 - purification, characterization, crystallization, and preliminaryX-ray diffraction data. J. Bacteriol., v. 173, n. 15, p. 4836-4841, 1991.

KRAJEWSKA, B. Application of chitin- and chitosan-based materials for enzyme immobilizations: a review. Enzyme Microb. Tech., v. 35, p. 126-139, 2004.

KULKARNI, M.G., DALAI, A.K. Waste cooking oil - an economical source for biodiesel: a review, Ind. Eng. Chem. Res., v. 45, p. 2901-2913, 2006.

LIMA, L. P. Produção de ácidos graxos assistida por ultrassom visando à produção de biodiesel. 2010. Dissertação (Mestrado em Engenharia Química) Depto. de Engenharia Química, UFC.

MORETO, E.; FETT, R. Tecnologia de óleos e gorduras vegetais na indústria de alimentos, São Paulo: Editora Varela, 1ª ed., p. 114-133, 1998.

SVENDSEN, A.; CLAUSEN, I.G.; PATKAR, S.A.; BORCH, K.; THELLERSEN, M.; Protein engineering of microbial lipases of industrial interest, Method. Enzymol., v. 317, p. 284-340, 1997.

TRUBIANO, G.; BORIO, D.; ERRAZU, A. Influence of the operating conditions and the external mass transfer limitations on the synthesis of fatty acid esters using a Candida antarctica lipase, Enzyme Microb. Tech., v. 40, p. 716-722, 2007. 